\title{
Endoscopic transforaminal lumbar discectomy in the treatment of multilevel disc herniations
}

Denglu Yan ( $\square$ yandenglu@163.com )

First People's Hospital of Zhaoqing https://orcid.org/0000-0001-6503-5077

\section{Zaiheng Zhang}

Shenzhen Baoan People's Hospital

\section{Zhi Zhang}

Third Hospital of Guangzhou Medical University

Research article

Keywords: Lumbar, Disc, Herniation, Endoscopic, Treatment

Posted Date: October 31st, 2019

DOI: https://doi.org/10.21203/rs.2.16661/v1

License: (1) This work is licensed under a Creative Commons Attribution 4.0 International License. Read Full License 


\section{Abstract}

Background There were no studies in literature of multiple level lumbar disc herniation treatment by endoscopic procedures. The purpose of this study was to evaluate the efficacy of endoscopic treatment multiple level lumbar disc herniation by compare to the one level disc herniation.

Methods A total of 267 patients of lumbar disc herniation who had endoscopic surgery were categorized into three different groups depending on the level number of endoscopic procedures. 78 cases had one level procedure (OL group), 54 cases had couple level procedures ( $C L$ group), and 35 cases had triple level procedures (TL group). Endoscopic discectomy procedures was performed and the clinical outcomes were recorded.

Results There was no intraoperative death in this series. The hospital day were no significant difference among three groups. The operational time and blood loss were biggest in triple levels procedures and lest in one level procedure. When take into the influence the numbers of disc herniation, there were no significant difference per level among three groups. The pain index and ODI score were better than preoperational in all patients, and there were no significant difference among three groups. The disk and foramen height, and lumbar lordosis were no significant difference compare to preoperative in all patients, and there were no significant difference among three groups. All patients achieved pain free accomplished all surgery procedures, no infection, and no dural tear of cerebrospinal fluid leakage complication.

Conclusions Endoscopic lumbar discectomy was effective and safe procedures in the treatment of multilevel lumbar disc herniation.

\section{Background}

With the development of minimally invasive endoscopic methods in spine surgery, a number of techniques have recently been developed that are applicable in the treatment of lumbar disc herniation. [1-6] The current trend of evolution lumbar spinal surgery has been toward endoscopic discectomy, which is a minimally invasive treatments aimed at removing nuclear material and decompression the nerve through devices were inserted percutaneous into intervertebral discs. $[7,8]$ Endoscopic discectomy is a well-established technique for nerve decompression by transforaminal to access the disc space, and transforaminal endoscopic lumbar discectomy has become population for its advantages and matured with time.[9-11,6] Endoscopic lumbar discectomy has become attractive procedures for lumbar disc herniation because it not only doesn't damage the spinal structures but also safe procedures with less trauma and faster recovery.[12-15]

Endoscopic lumbar discectomy is a minimally invasive for nerve decompression transforaminal, which is an anatomic safe corridor to the intervertebral disc space bounded medially by the traversing nerve root, laterally by the exiting nerve root, and caudally by the pedicle.[12,16,3,10] The endoscopic lumbar discectomy, which was performed through the transforaminal, can preserve the lumbar structures intact 
and the integrity of lumbar fascia and musculotendinous attachments.[17] There were many studies of endoscopic discectomy and showed good clinical results, which has the major advantages of sufficient decompression with no retraction on the nerve ganglion, less postoperative pain and earlier functional recovery.[2,18,19]

Degenerative changes and disc herniation are commonly found in lumbar spine and correlate with age, but only some people been involved one vertebral body and one disc level.[12,20-22,15] For those who had multiple level disc herniation is greatest in the age group of the population, and the most common cause of leg pain is disc prolapse which majorities at L4/L5, L5/S1, or L3/L4 levels. $[13,19,23,24]$ When the patients have multiple levels disc herniation which need endoscopic surgery, the endoscopic discectomy was performed at once or twice procedures? The purpose of this study was to evaluate the efficacy of endoscopic procedures in the treatment of multiple level lumbar disc herniation by compare to one level lumbar disc herniation in our clinical.

\section{Methods}

From June 2016 to July 2018, a total of 189 consecutive patients of lumbar disc herniation were had endoscopic discectomy because of leg pain. 189 patients initially fulfilled the study criteria, and 22 patients were lost to follow-up. Of the remaining 167 patients available for analysis, 78 cases had one level procedure of endoscopic discectomy (OL group, included 40 men and38 women with an average age of $41.16 \pm 5.39$ years), 54 cases had couple level surgery of endoscopic discectomy (CL group, included 31 men and 23 women with an average age of $45.73 \pm 6.48$ years), and 35 cases had triple level surgery of endoscopic discectomy (TL group, included 19 men and 16 women with an average age of $48.69 \pm 7.82$ years). The inclusion criteria were lumbar disc herniation which at L3/4, L4/5, or L5S1. Exclusion criteria included pathologic conditions of the lumbar spine (trauma, tumor, or infection). The pain history were $3.16 \pm 1.52$ years in OL patients, $3.28 \pm 1.37$ years in CL patients, and $3.28 \pm 1.37$ in TL patients. There were no significant difference among three group in age and sex distribution, older and the pain history $(P>0.05)$.

\section{Surgical procedures}

With the patient prone on a radiolucent operating table, the entry point is planned by preoperative imaging. The entry point was generally $10-13 \mathrm{~cm}$ from the midline, the skin is infiltrated with $1 \%$ lidocaine, and a long 18-gauge spinal needle was inserted from the entry point toward the midline, in the anterior-posterior view, under intermittent fluoroscopic guidance.[25,26] As usual, the discography was not performed. A guide wire was then inserted and a small skin incision made around it. The dilator was inserted, and the $7 \mathrm{~mm}$ working sheath was inserted over the dilator. AP and lateral C-arm projections confirm the correct location of the working sheath. The endoscope is advanced through the tunnel to visualize the migrated disc herniation directly. When the disc is visualized, the use of RF probe can help shrink the fragment to be easily removed with flexible endoscopic forceps (Figure 1ه2). Afterwards, the 
ventral epidural space is explored with an endoscopic nerve hook confirming that the herniated disc has been completely removed, and the traversing nerve root is free.

Figure 1 Female patient of 41 years with couple disc herniation at L4/5and L5S1 level underwent the procedures of endoscopic surgery. The working cannula was advanced to the sequestrated fragment, and foraminoplasty was performed at L5/S1 level.

The entry point of multiple level disc herniation is planned by preoperative imaging according the proximal level, and the route of the working cannulas that from the entry point to the target was planned and marked (Figure 1囚2). For multiple level disc herniation, the procedures was beginning performed severe levels to the next level (Figure $1 \otimes 2$ ). Since the surgery is done under local anesthesia, the surgeon has complete communication with the patient in procedures, by checking the movements of the affected limb and patient complaining sudden and severe radicular pain during the procedure. Foraminoplasty was performed when disc herniation at L5/S1 level, which removed small portions of anterolateral bone of facet articulation and its attached ligamentum flavum without interrupting the facet joint space, provided enough working space.[27,28] A gentle hammering and twisting motion of the trephine removed anterolateral bony portions of the facet join. Then the lateral surface of the dural sac and traversing root, the posterior longitudinal ligament, and posterolateral annulus of the disc of the contralateral portion could be observed. Finally, the endoscope and working cannula are removed from the patient, and the wound is closed with a single skin suture.

Figure 2 Male patient of 45 years with triple disc herniation at $L 3 / 4 \square L 4 / 5 \square$ and $L 5 S 1$ level underwent the procedures of endoscopic surgery. A $7.5 \mathrm{~mm}$ working cannula was advanced to the sequestrated fragment. Preoperative and postoperative surface making of anatomic disc center and the entrance point, and photography showed minimally invasive results.

\section{Critical of clinical outcomes}

Before surgery and at the one year follow-up, operation times, blood loss, hospital stays, pain (Visual

Analog Scale, VAS), functional disability (Oswestry Disability Index, ODI), and Mac Nab criteria were quantified in follow-up. All patients had preoperative and post-operative plain radiographs, computed tomography (CT) scans, and magnetic resonance (MR) images. The focus was to evaluate height of disk space and intervertebral foramen.

\section{Statistical analysis}

All measurements were performed by a single observer and are expressed as means $\pm S D$. Using the SPSS 17.0 statistics software, classic t-test and chi-square test were performed.

\section{Results}


There was no intraoperative death in this series. In ends 167 cases had follow-up at least one year and 22 cases lost, and the follow-up rate was $89.7 \%(78 / 87)$ in OL, 87.1\% (54/62) in CL, and 87.5\% (35/40) in TL $(P>0.05)$. The followed time was from 14 to 24 months (average 14 months), and average $13.16 \pm 1.57$ months on $\mathrm{OL}, 13.48 \pm 1.62$ months on $\mathrm{CL}$, and $13.56 \pm 1.73$ months on $T L$ patients $(P>0.05)$. The hospital days were no significant difference among three groups patients ( $3.25 \pm 1.47$ days in OL, $3.53 \pm$ 1.87 days in $C L$, and $3.68 \pm 1.69$ days in $T L, P>0.05$ ) (Table 1 ).

The average operational time were lest in OL patients ( $31.84 \pm 11.73$ minutes), modest in CL patients (54.68 \pm 13.55 minutes), and most in TL patients (76.74 \pm 12.89$)$. However, the average times spent in every level were no significant difference among three groups $(P>0.05)$ (Table 1). The average blood losses were less in OL patients $(21.58 \pm 11.69 \mathrm{~mL})$, modest in CL patients $(43.72 \pm 12.53 \mathrm{~mL})$, and most in TL patients $(62.83 \pm 11.71 \mathrm{~mL})$. Take into according the operational levels, the single level blood loss were no significant difference among three group patients $(P>0.05)$ (Table 1$)$.

Table 1 Follow up time and operation date of patients (Means \pm SD)

\begin{tabular}{lccccc}
\hline Group & \multicolumn{2}{c}{ Follow up* } & Operation time & Hospital days* & Blood loss \\
\cline { 2 - 3 } & Rate & Time (Month) & (Minutes) & (Days) & (mL) \\
\hline OL & $89.7 \%(78 / 87)$ & $13.16 \pm 1.57$ & $31.84 \pm 11.73$ & $3.25 \pm 1.46$ & $21.58 \pm 11.69$ \\
\hline CL & $87.1 \%(54 / 62)$ & $13.48 \pm 1.62$ & $54.68 \pm 13.55$ & $3.53 \pm 1.87$ & $43.72 \pm 12.53$ \\
\hline TL & $87.5 \%(35 / 40)$ & $13.56 \pm 1.73$ & $76.74 \pm 12.89$ & $3.68 \pm 1.69$ & $62.83 \pm 11.71$ \\
\hline
\end{tabular}

Note: $\mathrm{OL}=$ One level, $\mathrm{CL}=$ Couple level, $\mathrm{TL}=$ Triple level. $^{*}$, no significant difference $(\mathrm{P}>0.05)$

The pain index improved from $8.24 \pm 1.25$ to $1.12 \pm 0.47(\mathrm{P}<0.01)$ in OL patients, from $8.32 \pm 1.43$ to $1.25 \pm 0.38(P<0.01)$ in CL patients, and from $8.75 \pm 1.29$ to $1.48 \pm 0.36(P<0.01)$ in TL patients. There were no significant difference among three groups on the average change of VAS and ODI scores $(P>$ 0.05) (Table 2). The ODI improved from $62.55 \pm 12.63$ to $11.68 \pm 8.54(\mathrm{P}<0.01)$ in OL patients, from $63.57 \pm 14.86$ to $13.62 \pm 7.76(P<0.01)$ in CL patients, and from $66.81 \pm 13.49$ to $12.37 \pm 8.19(P<0.01)$ in TL patients.

Table 2 Clinical results date of patients (Means \pm SD)

\begin{tabular}{|c|c|c|c|c|c|c|}
\hline Group & \multicolumn{2}{|c|}{$\mathrm{OL}$} & \multicolumn{2}{|c|}{$\mathrm{CL}$} & \multicolumn{2}{|c|}{ TL } \\
\hline & Preoperative & Postoperative & Preoperative & Postoperative & Preoperative & Postoperative \\
\hline VAS & $8.24 \pm 1.25$ & $1.12 \pm 0.47$ & $8.32 \pm 1.43$ & $1.25 \pm 0.38$ & $8.75 \pm 1.29$ & $1.48 \pm 0.36$ \\
\hline ODI & $\begin{array}{c}62.55 \pm \\
12.63\end{array}$ & $11.68 \pm 8.54$ & $\begin{array}{c}63.57 \pm \\
14.86\end{array}$ & $13.62 \pm 7.76$ & $\begin{array}{c}66.81 \pm \\
13.49\end{array}$ & $12.37 \pm 8.19$ \\
\hline $\begin{array}{l}\mathrm{DH} \\
(\mathrm{mm})\end{array}$ & $8.79 \pm 2.45$ & $8.62 \pm 2.47$ & $8.54 \pm 2.51$ & $8.38 \pm 2.46$ & $8.47 \pm 2.69$ & $8.33 \pm 2.75$ \\
\hline $\begin{array}{l}\mathrm{FH} \\
(\mathrm{mm})\end{array}$ & $13.54 \pm 1.82$ & $13.42 \pm 1.94$ & $13.49 \pm 1.77$ & $13.25 \pm 1.58$ & $13.37 \pm 1.68$ & $13.15 \pm 1.72$ \\
\hline
\end{tabular}

Note: $\mathrm{OL}=$ One level, $\mathrm{CL}=$ Couple level, TL $=$ Triple level. $\mathrm{DH}=$ Disk height, FH = Foramen height.

The average disk space height decreased from preoperative $8.79 \pm 2.45 \mathrm{~mm}$ in preoperatively to $8.62 \pm$ $2.47 \mathrm{~mm}$ in postoperatively in OL patients $(P>0.05)$, and from $8.54 \pm 2.51 \mathrm{~mm}$ to $8.38 \pm 2.46 \mathrm{~mm}$ in $\mathrm{CL}$ patients $(P>0.05)$, and from $8.47 \pm 2.69 \mathrm{~mm}$ to $8.33 \pm 2.75 \mathrm{~mm}$ in TL patients $(P>0.05)$. There were no significant difference among three groups on the average change of disk height and intervertebral foramen height $(P>0.05)$. The mean foramen height decreased form $13.54 \pm 1.82 \mathrm{~mm}$ in preoperatively 
to $13.42 \pm 1.94 \mathrm{~mm}$ in postoperatively in $\mathrm{OL}$ patients $(\mathrm{P}>0.05)$, and from $13.49 \pm 1.77 \mathrm{~mm}$ to $13.25 \pm$ $1.58 \mathrm{~mm}$ in $\mathrm{CL}$ patents $(\mathrm{P}>0.05)$, and from $13.37 \pm 1.68 \mathrm{~mm}$ to $13.15 \pm 1.721 \mathrm{~mm}$ in $\mathrm{TL}$ patents $(P>$ 0.05) (Table 2).

All patients achieved pain free accomplished all surgery procedures, no infection, and no dural tear of cerebrospinal fluid leakage complication. On the Mac Nab criteria, there were no significant difference of good or excellent among three group patients (83.5\% in OL, 83.5\% in CL, and 84.6\% in TL, P>0.05). There were 27 cases of excellent, 10 cases of good, 5 cases of general, and 0 cases of poor in CL group; 28 cases of excellent, 11 case of good, 5 case of general, and 0 cases of poor in OL, and 28 cases of excellent, 11 case of good, 5 case of general, and 0 cases of poor in TL. There was one case in the OL group had L3/4 percutaneous endoscopic surgery with the needle broken in muscle when procedure. The partial needle had been moved by the percutaneous procedure. The surgery was performed and the clinical outcome of this case is good, and no complication. (Figure 3)

Figure 3 Shows the case of L3/4 percutaneous endoscopic surgery had the needle broken in muscle when procedure. The partial needle had been moved by the percutaneous procedure. The surgery was performed and the clinical outcome of this case is good, and no complication.

\section{Discussion}

Lumbar disc herniation in adults is characterized by the pain of leg and back pain due to disk degeneration, which involves a multitude of cellular and biochemical changes.[29,16,13] Discectomy was safe and effective surgery for disc herniation, and the decision about open or endoscopic discectomy to perform should mainly be based on the pathologic features of the lumbar spine.[11,20,24] Disc prolapse almost always start with an insidious onset of back pain followed at a later stage by root pain, and the appearance of the root pain may be accompanied by reduction or loss of the back pain.[19,14,4] With the minimal invasive techniques development, all sizes and types of disc herniation are possible in the hands of a skilled and experienced endoscopic surgeon. According to the data of this case, the pain index and ODI scores were significantly better the preoperative in three groups.

The endoscopic techniques rely heavily on the skill and experienced endoscopic surgeon, as well as the patient's anatomy relative to the location of the herniation and the ability to access the herniation. $[29,30,3]$ The aim of endoscopic discectomy was to relieve sciatica pain in disc herniation patients, which it's easy to decide and perform the surgery in one level disc herniation. However, the delimitation remains on the condition of two level disc herniation patients.[21,22] As for the precise diagnosed multilevel disc herniation, the causing symptoms of radiculopathy were more than one lever herniation.[13,18,23] Although the results of endoscopic discectomy very depending on the surgical skills and the sizes and types of herniation, it should be taken into consideration that multiple level disc herniation patients take once endoscopic discectomy procedure. According to the data of this case, the prevention of persisting leg pain were better in once procedures than twice which continue to experience back pain symptoms at other level. 
Disc herniation can changes of the lumbar spine and lead to leg pain and associated clinical symptoms, with the potential to severely impair function and quality of life.[1,30,31] The rationale of management of disco genic pain must be based on accurate diagnosis, for lumbar nerve root pain radiates in the distribution of one or more dermatomes and may be associated with neurological deficits.[32,22,19,10] The painful condition of the disc is currently identified by preoperative diagnostic, and the endoscopic not only procedure in the big disc herniation with leg pain, but also the small disc herniation with sciatica may be considered. $[32,21,14,3]$ Relative compare to the one level risk benefit ratio of the procedure, obviously benefits from multiple level therapy of foraminal endoscopic surgery. The disk and foramen height were no difference compare to preoperative in all patients in this series cases, which means once procedures of endoscopic can be safely performed in multiple level disc herniation and no infection on the disk and foramen height.

With lumbar spine techniques development, the procedures of discectomy and nerve decompression were completed by endoscopic procedures not only in one level of disc herniation, but also in two or three levels. $[2,13,18,15]$ Although multiple levels of disc herniation present a significant challenge for spinal surgeon when adopted the endoscopic other than traditional methods, the endoscopic discectomy procedure was safe and restore lumbar disk height and the lumbar lordosis as the results of this study. There was no difference between two group patients on the lumbar lordosis, which means two level endoscopic discectomy may be desirable to decompress the neural elements and restore lumbar lordosis. Its good results for multilevel disc herniation patients, endoscopic is a quick and safe operation resulting in neurological improvement from removed the pathologic tissue and restore lumbar lordosis.[23,24,10]

\section{Conclusions}

Based on the results of this study, endoscopic multilevel lumbar discectomy was effective and safe measure in the treatment of the multiple lumbar disc herniation. The information obtained from the multilevel disc herniation can be treatment by endoscopic once procedure allows the surgeon to more selectively pinpoint the lag and lumbar pain source and to determine use endoscopic procedures to treatment the source of pain.

\section{Abbreviations}

VAS: visual analog scale

ODI: Oswestry Disability Index

CT: computed tomography

MR: magnetic resonance

\section{Declarations}




\section{Ethical approval}

This study was approved by the hospital ethics committee of the First People's Hospital of Zhaoqing, Zhaoqing City, Guangdong Province, and all patients signed had informed consent.

\section{Consent for publication}

All authors of Denglu Yan, Zaiheng Zhang, and Zhi Zhang approve for publication

\section{Availability of data and material}

Data that support the findings of this study are available from the corresponding author on reasonable request.

\section{Competing interest}

Author Denglu Yan, Zaiheng Zhang, and Zhi Zhang declare that they have no conflict of interest.

\section{Funding}

No funding.

\section{Authors' contributions}

DY participated in the design of the study and drafted the manuscript. ZZh participated in the design of the study and coordination and helped to draft the manuscript. ZZ participated in the design of the study and performed the statistical analysis. All authors read and approved the final manuscript.

\section{Acknowledgements}

Not applicable.

\section{Author details}

${ }^{1}$ First People's Hospital of Zhaoqing, Zhaoqing, 526000, China

2 People's Hospital of Baoan, Shenzhen, 518101, China 
${ }^{3}$ Third Hospital of Guangzhou Medical University, Guangzhou, 510150, China

\section{References}

1. Choi DJ, Jung JT, Lee SJ, Kim YS, Jang HJ, Yoo B (2016) Biportal Endoscopic Spinal Surgery for Recurrent Lumbar Disc Herniations. Clin Orthop Surg 8 (3):325-329. doi:10.4055/cios.2016.8.3.325

2. Choi KC, Kim JS, Kang BU, Lee CD, Lee SH (2011) Changes in back pain after percutaneous endoscopic lumbar discectomy and annuloplasty for lumbar disc herniation: a prospective study. Pain Med 12 (11):1615-1621. doi:10.1111/j.1526-4637.2011.01250.x

3. Iprenburg M, Wagner R, Godschalx A, Telfeian AE (2016) Patient radiation exposure during transforaminal lumbar endoscopic spine surgery: a prospective study. Neurosurg Focus 40 (2):E7. doi:10.3171/2015.11.FOCUS15485

4. Mayer HM, Brock M (1993) Percutaneous endoscopic lumbar discectomy (PELD). Neurosurg Rev 16 (2):115-120

5. Wang X, Zhou S, Bian Z, Li M, Jiang W, Hou C, Zhu L (2018) Unilateral percutaneous endoscopic debridement and drainage for lumbar infectious spondylitis. J Orthop Surg Res 13 (1):306. doi:10.1186/s13018-018-1009-5

6. Li X, Dou Q, Hu S, Liu J, Kong Q, Zeng J, Song Y (2016) Treatment of cauda equina syndrome caused by lumbar disc herniation with percutaneous endoscopic lumbar discectomy. Acta Neurol Belg 116 (2):185-190. doi:10.1007/s13760-015-0530-0

7. Komp M, Hahn P, Oezdemir S, Giannakopoulos A, Heikenfeld R, Kasch R, Merk H, Godolias G, Ruetten $S$ (2015) Bilateral spinal decompression of lumbar central stenosis with the full-endoscopic interlaminar versus microsurgical laminotomy technique: a prospective, randomized, controlled study. Pain Physician 18 (1):61-70

8. Kim JE, Choi DJ, Park EJ (2018) Clinical and Radiological Outcomes of Foraminal Decompression Using Unilateral Biportal Endoscopic Spine Surgery for Lumbar Foraminal Stenosis. Clin Orthop Surg 10 (4):439-447. doi:10.4055/cios.2018.10.4.439

9. Lu S, Xu YQ, Ding ZH, Wang YL, Shi JH, Zhong SZ (2008) Clinical anatomic study of the lower lumbar anterolateral vein: with respect to retroperitoneal endoscopic surgery. Chin J Traumatol 11 (2):110-113. doi:10.1016/s1008-1275(08)60023-1

10. Lee CW, Yoon KJ (2019) The Usefulness of Percutaneous Endoscopic Technique in Multifocal Lumbar Pathology. Biomed Res Int 2019:9528102. doi:10.1155/2019/9528102

11. Yokosuka J, Oshima Y, Kaneko T, Takano Y, Inanami H, Koga H (2016) Advantages and disadvantages of posterolateral approach for percutaneous endoscopic lumbar discectomy. J Spine Surg 2 (3):158-166. doi:10.21037/jss.2016.09.03

12. Liu W, Li Q, Li Z, Chen L, Tian D, Jing J (2019) Clinical efficacy of percutaneous transforaminal endoscopic discectomy in treating adolescent lumbar disc herniation. Medicine (Baltimore) 98 (9):e14682. doi:10.1097/MD.0000000000014682 
13. Yeom KS, Choi YS (2011) Full endoscopic contralateral transforaminal discectomy for distally migrated lumbar disc herniation. J Orthop Sci 16 (3):263-269. doi:10.1007/s00776-011-0048-0

14. Lee SH, Kang BU, Ahn Y, Choi G, Choi YG, Ahn KU, Shin SW, Kang HY (2006) Operative failure of percutaneous endoscopic lumbar discectomy: a radiologic analysis of 55 cases. Spine (Phila Pa 1976) 31 (10):E285-290. doi:10.1097/01. brs.0000216446.13205.7a

15. Jang JS, An SH, Lee SH (2006) Transforaminal percutaneous endoscopic discectomy in the treatment of foraminal and extraforaminal lumbar disc herniations. J Spinal Disord Tech 19 (5):338-343. doi:10.1097/01.bsd.0000204500.14719.2e

16. Hoogland T, van den Brekel-Dijkstra K, Schubert M, Miklitz B (2008) Endoscopic transforaminal discectomy for recurrent lumbar disc herniation: a prospective, cohort evaluation of 262 consecutive cases. Spine (Phila Pa 1976) 33 (9):973-978. doi:10.1097/BRS.0b013e31816c8ade

17. Sairyo K, Goel VK, Masuda A, Biyani A, Ebraheim N, Mishiro T, Terai T (2005) Biomechanical rationale of endoscopic decompression for lumbar spondylolysis as an effective minimally invasive procedure - a study based on the finite element analysis. Minim Invasive Neurosurg 48 (2):119-122. doi:10.1055/s-2004-830223

18. Passacantilli E, Lenzi J, Caporlingua F, Nardone A, Cannizzaro D, Pescatori L, Santoro A (2016) Full endoscopic transforaminal endoscopic approach for symptomatic lumbar disc herniation, our experience. J Neurosurg Sci 60 (3):410-412

19. Kamson S, Trescot AM, Sampson PD, Zhang Y (2017) Full-Endoscopic Assisted Lumbar Decompressive Surgery Performed in an Outpatient, Ambulatory Facility: Report of 5 Years of Complications and Risk Factors. Pain Physician 20 (2):E221-E231

20. Tu Z, Li YW, Wang B, Lu G, Li L, Kuang L, Dai Y (2017) Clinical Outcome of Full-endoscopic Interlaminar Discectomy for Single-level Lumbar Disc Herniation: A Minimum of 5-year Follow-up. Pain Physician 20 (3):E425-E430

21. Lee SH, Chung SE, Ahn Y, Kim TH, Park JY, Shin SW (2006) Comparative radiologic evaluation of percutaneous endoscopic lumbar discectomy and open microdiscectomy: a matched cohort analysis. Mt Sinai J Med 73 (5):795-801

22. Shiboi R, Oshima Y, Kaneko T, Takano Y, Inanami H, Koga H (2017) Different operative findings of cases predicted to be symptomatic discal pseudocysts after percutaneous endoscopic lumbar discectomy. J Spine Surg 3 (2):233-237. doi:10.21037/jss.2017.05.07

23. Teli M, Lovi A, Brayda-Bruno M, Zagra A, Corriero A, Giudici F, Minoia L (2010) Higher risk of dural tears and recurrent herniation with lumbar micro-endoscopic discectomy. Eur Spine J 19 (3):443450. doi:10.1007/s00586-010-1290-4

24. Lee JH, Lee SH (2018) Which clinical and radiological variables could predict clinical outcomes of percutaneous endoscopic lumbar discectomy for treatment of patients with lumbosacral disc herniation? Spine J 18 (8):1338-1346. doi:10.1016/j.spinee.2017.12.010

25. Kim HS, Paudel B, Jang JS, Lee K, Oh SH, Jang IT (2018) Percutaneous Endoscopic Lumbar Discectomy for All Types of Lumbar Disc Herniations (LDH) Including Severely Difficult and 
Extremely Difficult LDH Cases. Pain Physician 21 (4):E401-E408

26. Hu QF, Pan H, Fang YY, Jia GY (2018) Percutaneous endoscopic lumbar discectomy for high-grade down-migrated disc using a trans-facet process and pedicle-complex approach: a technical case series. Eur Spine J 27 (Suppl 3):393-402. doi:10.1007/s00586-017-5365-3

27. Lee S, Kim SK, Lee SH, Kim WJ, Choi WC, Choi G, Shin SW (2007) Percutaneous endoscopic lumbar discectomy for migrated disc herniation: classification of disc migration and surgical approaches. Eur Spine J 16 (3):431-437. doi:10.1007/s00586-006-0219-4

28. Chung J, Kong C, Sun W, Kim D, Kim H, Jeong H (2019) Percutaneous Endoscopic Lumbar Foraminoplasty for Lumbar Foraminal Stenosis of Elderly Patients with Unilateral Radiculopathy: Radiographic Changes in Magnetic Resonance Images. J Neurol Surg A Cent Eur Neurosurg 80 (4):302-311. doi:10.1055/s-0038-1677052

29. Wang YP, Zhang W, Zhang J, Sun YP, An JL, Ding WY (2017) Analysis of the clinical effects of transforaminal endoscopic discectomy on lumbar disk herniation combined with common peroneal nerve paralysis: a 2-year follow-up retrospective study on 32 patients. J Pain Res 10:105-112. doi:10.2147/JPR.S120463

30. Gadjradj PS, van Tulder MW, Dirven CM, Peul WC, Harhangi BS (2016) Clinical outcomes after percutaneous transforaminal endoscopic discectomy for lumbar disc herniation: a prospective case series. Neurosurg Focus 40 (2):E3. doi:10.3171/2015.10.FOCUS15484

31. Dabo X, Ziqiang C, Yinchuan Z, Haijian N, Kai C, Yanbin L, Qiang F, Chuanfeng W (2016) The Clinical Results of Percutaneous Endoscopic Interlaminar Discectomy (PEID) in the Treatment of Calcified Lumbar Disc Herniation: A Case-Control Study. Pain Physician 19 (2):69-76

32. Lee CW, Yoon KJ, Ha SS (2019) Comparative Analysis between Three Different Lumbar Decompression Techniques (Microscopic, Tubular, and Endoscopic) in Lumbar Canal and Lateral Recess Stenosis: Preliminary Report. Biomed Res Int 2019:6078469. doi:10.1155/2019/6078469

\section{Figures}

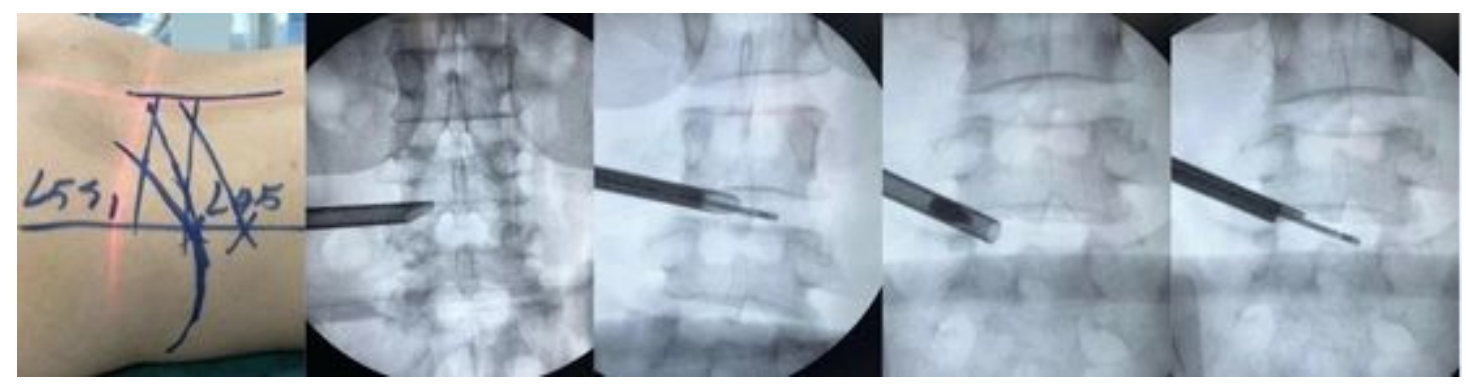

\section{Figure 1}

Female patient of 41 years with couple disc herniation at L4/5and L5S1 level underwent the procedures of endoscopic surgery. The working cannula was advanced to the sequestrated fragment, and foraminoplasty was performed at L5/S1 level. 

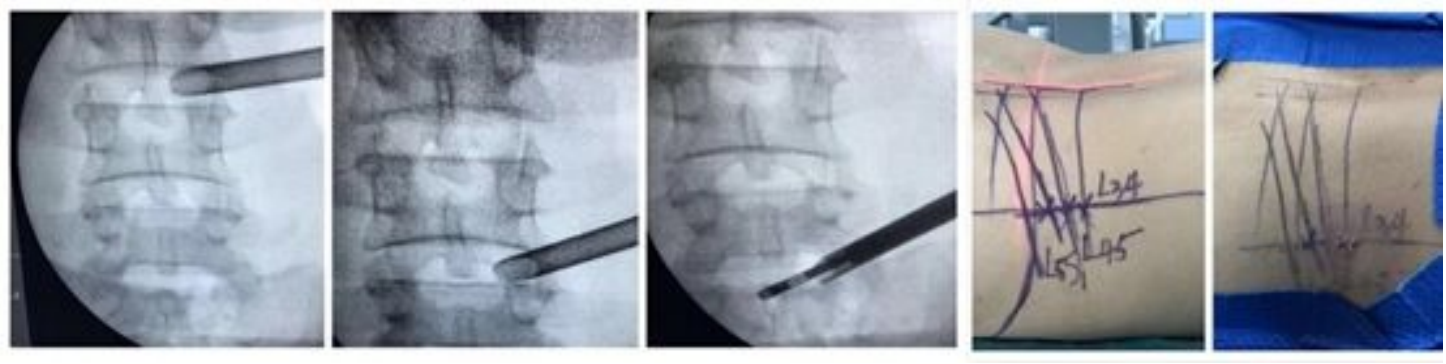

\section{Figure 2}

Male patient of 45 years with triple disc herniation at L3/4 LL4/5ロand L5S1 level underwent the procedures of endoscopic surgery. A $7.5 \mathrm{~mm}$ working cannula was advanced to the sequestrated fragment. Preoperative and postoperative surface making of anatomic disc center and the entrance point, and photography showed minimally invasive results.
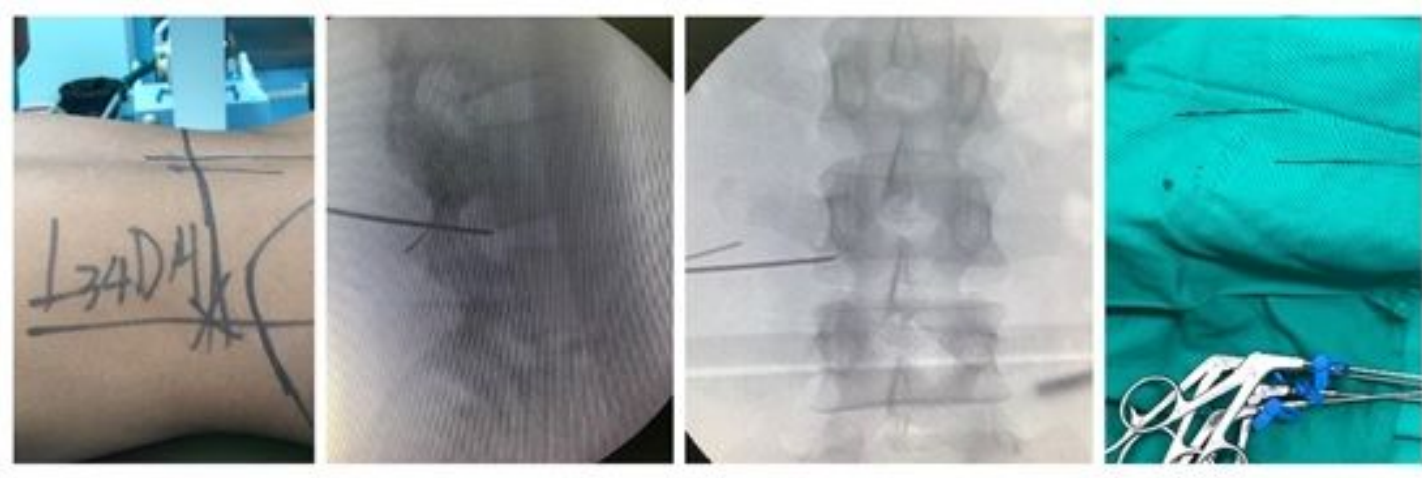

\section{Figure 3}

Shows the case of L3/4 percutaneous endoscopic surgery had the needle broken in muscle when procedure. The partial needle had been moved by the percutaneous procedure. The surgery was performed and the clinical outcome of this case is good, and no complication. 